\title{
War Surgery: Working with Limited Resources in Armed Conflict and Other Situations of Violence, by Christos Giannou and Marco Baldan
}

\author{
ICRC, Geneva, 2009, Volume 1, 351 pp., Illus., Photos, Including Multimedia CD-ROM, \\ $21 \times 30 \mathrm{~cm}$, English, CHF 35. Also available at http://www.icrc.org/web/eng/ \\ siteeng0.nsf/htmlall/p0973/\$File/ICRC_002_0973.PDF
}

\author{
Martin Schreiber \\ Published online: 24 November 2009 \\ (C) Société Internationale de Chirurgie 2009
}

\section{Introduction}

This book, written by Drs. Giannou and Baldan-two International Committee of the Red Cross head surgeonswas originally intended to be the 4th edition of Surgery for Victims of War. This book focuses on such broad topics as the historical development of the ICRC, International Humanitarian Law, how to set up a hospital in a hostile environment with limited resources, triage, ballistics, and basic surgical principles of resuscitation and surgical management of combat victims, both military and civilian. The work obviously represents the wealth of experience shared by the authors.

This book is a comprehensive manual describing essentially all aspects of the care of the wounded during conflicts and natural disasters. It provides step-by-step instructions concerning the moral obligations of those delivering care, how to deal with the local politics, the structure of a hospital, how to score wounds in a systematic fashion, and surgical and medical management of patients. The book is relevant to all members of the health-care team, including administrators, emergency personnel, nurses, and physicians. It does an excellent job of differentiating medical care delivered in austere and hostile environments with minimal resources from first-world civilian medical care delivered in an urban environment with essentially limitless resources. I would recommend this book to anyone in the medical field who is deploying to a military setting, and especially to individuals who intend to deliver medical care in austere environments with significantly less resources than they are accustomed to having.

Volume 1 is accompanied by a CD that includes other ICRC publications addressing war wounded like Surgery for Victims of War, Wound Management, Fracture Management, and Amputation. The CD also includes a movie that summarizes the management of combat casualties. Various forms for collecting patient data, evaluating a standing hospital for the management of war wounded, and issues related to medical care delivered in a conflict scenario are also addressed on the $\mathrm{CD}$. The entire volume is available free online at http://www.icrc.org/web/eng/ siteeng0.nsf/htmlall/p0973/\$File/ICRC_002_0973.PDF.

Overall, this book is an outstanding manual of textbook quality that should be obligatory reading for anyone who intends to care for war wounded in rough environments. It is distinctly different from other publications like Emergency War Surgery and War Surgery in Afghanistan and Iraq in its comprehensive approach to all aspects of medical care delivered in these difficult settings and its focus on pure humanitarianism. My only criticism of this publication relates to the size of the illustrations. Many of the pictures, especially of the wounds, are too small to visualize the points the authors are trying to transmit. This is a minor detraction from an excellent publication.

M. Schreiber ( $\square)$

Division of Trauma, Critical Care and Acute Care Surgery, Oregon Health and Science University, 3181 SW Sam Jackson Park Road, Mail Code L611, Portland, OR 97239-3098, USA

e-mail: schreibm@ohsu.edu 